\title{
An Evaluation on the Flexural Strength of Heat Cure Polymethyl methacrylate Denture Base Resin with and without Reinforcement of Polyethylene Fiber
}

\author{
Pathak $\mathrm{B}^{1 *}$, Mathema $\mathrm{S}^{2}$, Sharma $\mathrm{R}^{3}$ \\ ${ }^{1}$ Assistant Professor, Department of Prosthodontics, People's Dental College and Hospital, Kathmandu, Nepal \\ ${ }^{2}$ Professor, Department of Prosthodontics, People's Dental College and Hospital, Kathmandu, Nepal \\ ${ }^{3}$ Lecturer, Department of Prosthodontics, Nepal Medical College, Kathmandu, Nepal
}

\begin{abstract}
Introduction: Polymethyl methacrylate as denture base material is not ideal in many aspects. The primary problem is its poor strength characteristics, including low impact and flexural strength. The fatigue failure occurs when the denture base deforms repeatedly through occlusal forces, hence dentures tend to break during usage in due course of time.

The aim of this study was to measure and compare the flexural strength of heat cure Polymethyl methacrylate denture base resin with and without reinforcement of polyethylene fiber.

Method: A total of 52 specimens (maxillary complete denture) were divided into 2 groups(n=26); Group A(Control): Dentures without reinforcement, Group B: Dentures reinforced with Polyethylene fiber. All specimens were subjected to three-point bending test in UTM. A flexural load was applied to each maxillary complete denture at a speed of $5 \mathrm{~mm} / \mathrm{min}$ until fracture and the flexural load required to break specimen was recorded.

Results: The mean values and standard deviation of each test specimen group was calculated and statistical analysis of obtained values was done using ANOVA. Mean flexural strength for Group A was $142.66 \pm 29.95 \mathrm{MPa}$ and Group B was $218.88 \pm 29.96 \mathrm{MPa}$. Group comparison showed a statistically significant difference $(\mathrm{p}<0.001)$ between group A and B. This suggested that flexural strength for specimens reinforced with Polyethylene fibers was significantly higher than specimens without reinforcement.
\end{abstract}

Conclusion: Reinforcement of heat cure polymethyl methacylate denture base resin with polyethylene fiber resulted in significant increase in flexural strength.

Key words: Denture fractures, flexural strength, heat polymerized acrylic resin, reinforcement, repairs.

\section{Introduction}

$\mathrm{P}$ olymethyl methacrylate (PMMA) as denture base material dates back to $1937^{1}$ but is still the most predominantly used denture base material because of its availability, dimensional stability, and excellent esthetics, ease of processing and repair, compatibility with oral tissues. However, it is still far from ideal

\section{*Corresponding Author}

Dr. Binita Pathak, Assistant Professor, Department of Prosthodontics and Maxillofacial Prosthetics, People's Dental College and Hospital, Kathmandu, Nepal.

E-mail:drbinitapathak@gmail.com materials because of its low mechanical strength, brittleness and low thermal conductivity. ${ }^{2}$

Denture bases are subjected to different stresses, mainly flexural and impact $^{3}$ during its processing stages and after being placed in service. Studies have shown that $68 \%$ of acrylic resin dentures break within a few years of fabrication; maxillary complete denture being fractured by a combination of fatigue and impact failure, whereas for mandibular dentures, $80 \%$ of fractures by impact. Three approaches to improve the strength are: use of an alternative material (polyamides and polycarbonates) the 
chemical modification of a denture base material by such as copolymerization with a rubber graft copolymer $^{4}$ or the addition of cross-linking agents $^{5}$ and the reinforcement of PMMA with other materials such as carbon fibers ${ }^{6}$, glass fibers $^{7}$ and ultrahigh modulus polyethylene fibers ${ }^{8}$ or metal inserts ${ }^{9}$ into denture bases.

\section{Materials and Methods}

This in-vitro study was done in Department of Prosthodontics and Maxillofacial Prosthetics, People's Dental College and Hospital, Nepal.

Total of 52 test specimens (maxillary complete dentures) were fabricated for the study, which were divided into 2 Groups of 26 specimens each $(n=26)$ depending upon different reinforcements, Group A (Control) comprised of unreinforced denture and Group B, denture was reinforced with Polyethylene fiber.

\section{Preparation of experimental specimens}

For fabrication of standard specimen, a thermoplastic sheet was used to form a temporary denture base. Wax occlusion rim of ideal dimensions was fabricated with modeling wax followed by ideal teeth arrangement and wax up and carving done. After curing, the standard specimen was deflasked, grossly finished and polished. This standard specimen was duplicated into Polyvinyl siloxane (putty consistency) elastomeric material mix to obtain a putty mould [Figure 1]. Teeth set of same size and mould as used in fabrication of the Standard specimen were used. Each tooth was placed into tooth space in putty mould and the molten wax was poured to fill the mould, then stone cast was placed into mould. After cooling duplicated waxed trial denture was retrieved [Figure 1]. The trial denture retrieved was carved, adjusted again to $2.5 \mathrm{~mm}$ thickness. 52 of trial dentures were fabricated in similar manner.

The waxed trial dentures were then invested, dewaxing was done and thin layer of sodium alginate separating media (Cold Mould seal, DPI) was applied except on teeth surfaces. Equal amount of dough was placed in both halves of flask. After trial packing, reinforcing agents were placed according to groups divided. For Group A, packing was done without any reinforcement, 26 dentures fabricated in similar way. For Group B, Polyethylene fiber (Ribbond $30 \mathrm{~mm} \times 2 \mathrm{~mm}$ ) were cut into $3 \mathrm{~mm}$ in length and wetted in 10 drops of monomer before trial closure and at dough stage, trial packing was done. After that previously wetted Polyethylene fiber $1 \%$ by weight of polymer were placed in between halves of flask [Figure 2].

For both groups, final closure was done by applying pressure in hydraulic press. Bench curing was done for 30 minutes and acrylization was done using short curing cycle. The flasks were left for bench cooling overnight. Next day the dentures were retrieved, grossly finished and polished. After fabrication of all 52 test specimens, they were numbered according to groups (A1-A26, B1-B26). Then they were stored in room temperature distilled water for 1 week before testing to simulate the intra-oral environment.

\section{Testing of specimens}

The flexural load was evaluated by the threepoint bending test at a cross head speed of $5 \mathrm{~mm} / \mathrm{min}$ using Universal Testing Machine (Shimadzu). The dentures were placed on platform of machine with customized jig and flexural load was applied to center of tissue surface of each denture with a $25 \mathrm{~mm}$ diameter ball attachment [Figure 3]. The specimen was loaded until fracture [Figure 3] and the flexural load required to break specimen was recorded from digital monitor of testing machine for all specimens.

Then Flexural strength was calculated in N/mm ${ }^{2}$ (MPa) by means of the standard relation. $\mathrm{S}=3$ $\mathrm{LP} / 2 \mathrm{WT}^{2}$, where $\mathrm{S}$ is the Flexural strength, $\mathrm{P}$ 
is the fracture load $(\mathrm{N}), \mathrm{L}$ the distance between supports $(\mathrm{mm}), \mathrm{W}$ the specimen width(mm), and $\mathrm{T}$ the specimen thickness( $\mathrm{mm})$.

After calculation, data was entered on SPSS ver20 and statistical analysis was done. The mean values and standard deviation of each test specimen group was calculated and statistical analysis of obtained values was done using ANOVA. All results were considered statistically significant if $\mathrm{P}<0.05$.

\section{Results}

Mean flexural strength value for Group A was $142.66 \pm 29.95 \mathrm{MPa}$ and Group B was $218.88 \pm 29.96 \mathrm{MPa}$ [Table 1]. Multiple group comparison showed a statistically significant difference between groups $\mathrm{A}$ and $\mathrm{B}(\mathrm{p}<0.001)$ [Table 2]. This suggested the greater flexural strength for specimens reinforced with Polyethylene fibers as compared to unreinforced specimens.

Table 1: Mean Flexural strength and Standard Deviation values for each group (Reference Mean of Control group 142.66 MPa)

\begin{tabular}{|c|c|c|c|c|c|c|}
\hline & n & Minimum & Maximum & Range & Mean & $\begin{array}{c}\text { Standard } \\
\text { Deviation }\end{array}$ \\
\hline Group A & 26 & 95.70 & 188.10 & 92.40 & 142.66 & 29.95 \\
\hline Group B & 26 & 174.90 & 270.60 & 95.70 & 218.88 & 29.96 \\
\hline
\end{tabular}

Table 2: Comparison of Mean Flexural strength of various groups with that of control group.

\begin{tabular}{|c|c|c|c|c|}
\hline \multirow{2}{*}{ Groups } & \multirow{2}{*}{$\begin{array}{c}\text { Mean } \\
\text { Difference }\end{array}$} & \multicolumn{2}{|c|}{$\begin{array}{l}\text { 95\% Confidence interval of the } \\
\text { Differences }\end{array}$} & \multirow{2}{*}{ p value* } \\
\hline & & Lower & Upper & \\
\hline $\begin{array}{l}\text { Dentures reinforced with } \\
\text { Polyethylene fiber (Group B) }\end{array}$ & 76.22 & 64.11 & 88.32 & $<0.001$ \\
\hline
\end{tabular}

$* p<0.05$ statistically significant
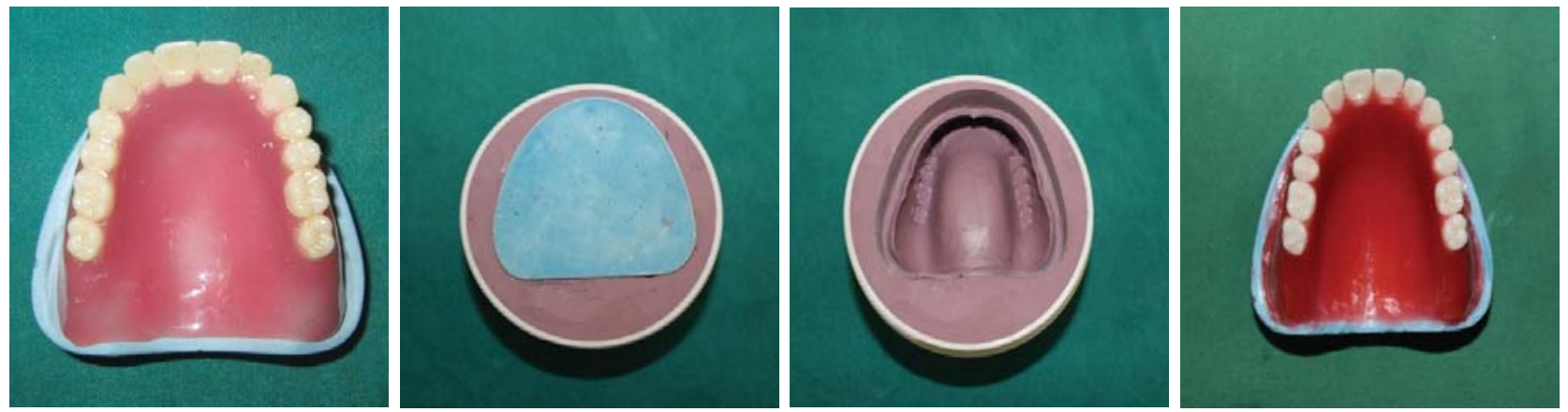

Figure 1: Fabrication of Putty mould and Trial denture
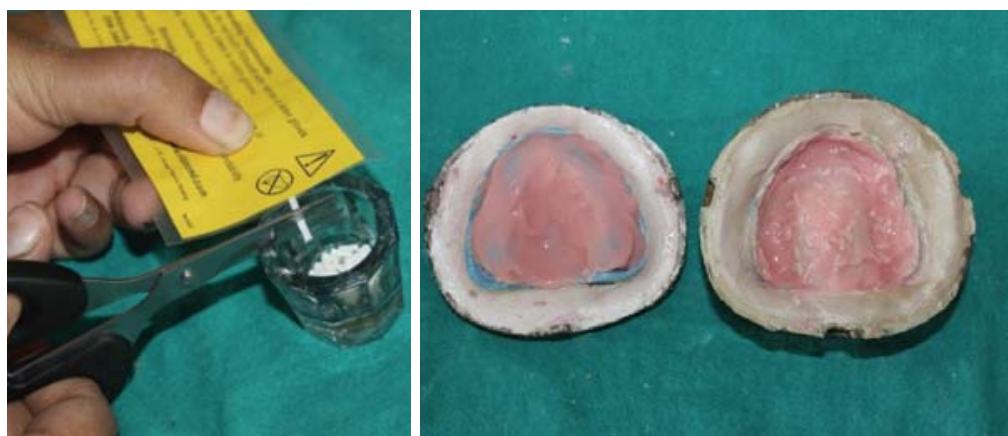

Figure 2: Packing with pre-wetted Polyethylene fiber

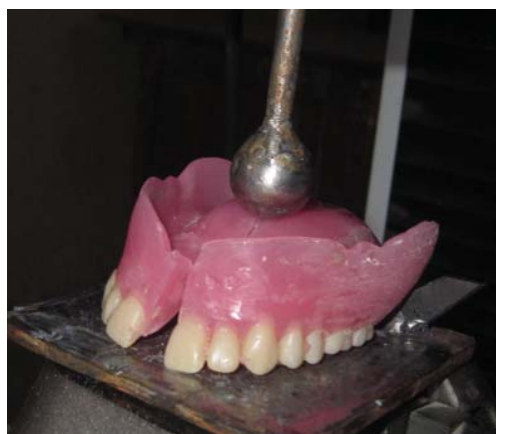

Figure 3: Fracture of specimen 


\section{Discussion}

Although individual denture bases may be made from metals or metal alloys, majority of denture bases are fabricated using common polymers chosen based on availability, excellent appearance, ease in processing, reparability, dimensional stability, handling characteristics. Despite the widespread use of PMMA, low impact and fatigue strength ${ }^{10}$ of material itself may result in failure of dentures and expense in terms of financial cost and inconvenience to the patient when repairs are carried out. Fracture of a denture is an important problem not only for patients but also for dentists and dental laboratory technicians. ${ }^{11}$ In most situations, fractures occur in the midline of the denture base. ${ }^{12}$ This location of fracture occurs more often in maxillary dentures than in mandibular dentures (ratio of maxillary to mandibular denture base fractures is $2: 1) .{ }^{13}$

Although various materials and methods have been proposed for repairing fractured denture bases, repairing with auto polymerized resin is much weaker (approximately $60 \%$ to $65 \%$ of the original material ${ }^{14}$ than the originally used heat polymerized denture resin. ${ }^{15}$ Doubling the thickness of the denture was one of the early attempts to increase the strength of acrylic dentures. ${ }^{16}$ Recently, much attention has been directed towards the addition of various types of fibers like carbon fiber ${ }^{17,18}$ polyethylene fiber $^{19,20}$ and glass fiber ${ }^{21,22}$ to acrylic resins in an attempt to improve its mechanical properties. Reinforcement with fibers enhances the mechanical strength characteristics of denture bases, such as the transverse strength, ultimate tensile strength and impact strength. ${ }^{23}$ Gutteridge $\mathrm{DL}^{24}$ in 1993 suggested that the use of short lengths of $3 \mathrm{~mm}$ or $6 \mathrm{~mm}$ Ultra-high modulus polyethylene (UHMPE) fiber is an appropriate, effective and technically acceptable means of reinforcing PMMA. Some investigators have found that the flexural properties of UHMWPE- reinforced denture base polymer showed no significant increase in flexural strength. ${ }^{19,25}$

Flexural strength was used in this study because this test more closely represents the type of loading applied to a denture in the mouth. ${ }^{26}$ The test specimens were maxillary complete denture because typical fatigue failure occurs in maxillary complete denture as evidenced by a midline fracture. ${ }^{13,27}$ Yoshida et al. ${ }^{9}$ in 2011, Yadav et al. ${ }^{28}$ in 2012 also have used maxillary complete denture as test specimens and threepoint bending test as measure for flexural strength in their study.

\section{Limitation}

1. In-vitro static load tests differ from intraoral dynamic conditions.

2. Since test specimen in this study involves complex design, uniform thickness of specimen cannot be ascertained which might affect flexural strength.

3. Some variability might be incorporated during selection of material, finishing and polishing and storage of specimens.

\section{Conclusion}

Within the limitations of this in vitro study, the following conclusion can be drawn: Reinforcement of heat cure polymethyl methacylate denture base resin with polyethylene fibre resulted in significant increase in flexural strength.

\section{References}

1. Peyton FA. History of resins in dentistry. Dent Clin North Am. 1975; 19: 211-22.

2. Brady AP, Lee H, Orlowski JA. Thermal conductivity studies of composite dental restorative materials. J Biomed Mater Res. 1974;8: 471-85.

3. IH Tacir, JD Kama. Flexural properties of glass fibre reinforced acrylic resin polymers. Aust Dent J. 2006;51(1): 52-6. 
4. Rodford R. The development of high impact strength denture-base materials. J Dent. 1986;14: 214-7.

5. Oku J. Impact properties of acrylic denture base resin: Impact properties of cross-linked polymers. Dent Mater. 1989; 8: 215-22.

6. Schreiber CK. Polymethyl methacrylate reinforced with carbon fibres. Br Dent J. 1971;130: 29-30.

7. Narva KK, Lassila VP, Vallittu PK. The static strength and modulus of fiber reinforced denture base polymer. Dent Mater. 2005;21: 421-428.

8. Braden M, Davy KW, Parker S, Ladizesky NH, Ward IM. Denture base poly(methyl methacrylate) reinforced with ultra-thin modulus polyethylene fibers. Br Dent J. 1988;164: 10913.

9. Yoshida K, Takahashi Y, Shimizu H. Effect of embedded metal reinforcements and their location on the fracture resistance of acrylic resin complete dentures.J Prosthodont. 2011;20: 366-71.

10. Smith DC. Recent developments and prospects in dental polymers. J Prosthet Dent. 1962;12: 1066-78.

11. Teraoka F, Nakagawa M, Takahashi J. Adaptation of acrylic dentures reinforced with metal wire. J Oral Rehabil. 2001; 28: 937-42.

12. Smith DC. The acrylic denture: Mechanical evaluation of midline fracture. $\mathrm{Br}$ Dent J.1961;110: 257-67.

13. Dabbar UR, Huggett R, Harrison A. Denture fracture-survey. Br Dent J. 1994;176: 342-5.

14. Rached RN, Powers JM, Del Bel Cury AA. Repair strength of autopolymerizing, microwave, and conventional heat-polymerized acrylic resins. J Prosthet Dent. 2004; 92: 79-82.

15. Dyer RA, Howlett JA. Dimensional stability of denture bases following repair with microwave resin. J Dent. 1994; 22: 236-41.

16. McCabe JF. Anderson's Applied Dental Materials. 6th ed. Blackwell Scientific Publications. Oxford, London, Edinburgh.1985; Pp: 43, 75-91.

17. Yazdanie N, Mahood M. Carbon fiber acrylic resin composite: an investigation of transverse strength. J Prosthet Dent. 1985;54: 543-7.
18. Ekstrand K, Ruyter IE, Wellendorf H. Carbon graphite fiber reinforced poly (methyl methacrylate) :properties under dry and wet conditions. J Biomed Mater Resear. 1987;21: 1065-80.

19. Dixon DL, Breeding LC. The transverse strengths of three denture base resins reinforced with polyethylene fibres. J Prosthet Dent. 1992;67: 417-9.

20. Ladizesky NH, Cheng YY, Chow TW, Ward IM. Acrylic resin reinforced with chopped high performance polyethylene fiber-properties and denture construction. Dent mater 1993;9(2):128-35.

21. Solnit GS. The effect of methyl methacrylate reinforcement with silane-treated and untreated glass fibers. J Prosthet Dent. 1991;66(3):310-4.

22. Vallittu PK. Flexural properties of acrylic resin polymers reinforced with unidirectional and woven glass fibers.J Prosthet Dent. 1999;81: 318-26.

23. Uzun G, Hersek N,Tincer T. Effect of five woven fiber reinforcements on the impact and transverse strength of a denture base resin. J Prosthet Dent. 1999;81: 616-20.

24. Gutteridge DL. The effect of variations in fibre length on the impact strength of poly(methyl methacrylate) resin reinforced with ultrahigh-modulus polyethylene fibre.Clinical Mater.1993;12:137-40.

25. Williamson DL, Boyer DB, Aquilino SA, Leary JM. Effect of polyethylene fiber reinforcement on the strength of the denture base resins polymerized by microwave energy. J Prosthet Dent. 1994;72: 635-8.

26. Shimizu H, Yoshinaga M, Takahashi Y, Habu T. Effect of surface preparations on the repair strength of denture base resin.Int Chin J Dent. 2002; 2:126-33.

27. Vallittu PK, Lassila VP, Lappalainen R. Evaluation of damage to removable denture in two cities in Finland. Acta Odontol Scand. 1993;51: 363-9.

28. Yadav P, Mittal R. Effect of incorporation of silane-treated silver and aluminum microparticles on strength and thermal conductivity of PMMA. J Prosthodont. 2012; 21: 546-51. 